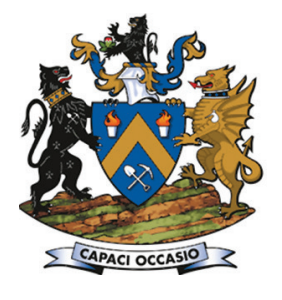

\title{
Adaptive simultaneous stochastic optimization of a gold mining complex: A case study
}

\author{
Z. Levinson ${ }^{1}$ and R. Dimitrakopoulos ${ }^{1}$
}

Affiliation:

${ }^{1}$ COSMO - Stochastic Mine

Planning Laboratory, Department of Mining and Materials

Engineering, McGill University,

Montreal, Quebec, Canada.

Correspondence to:

Z. Levinson

Email:

zachary.levinson@mail.mcgill.ca

Dates:

Received: 15 Jul. 2019

Revised: 24 Nov. 2019

Accepted: 5 Dec. 2019

Published: March 2020

\section{How to cite:}

Levinson, Z. and

Dimitrakopolous, $\mathrm{R}$.

Adaptive simultaneous stochastic optimization of a gold mining

complex: A case study.

The Southern African Insitute of

Mining and Metallurgy

DOI ID:

http://dx.doi.org/10.17159/24119717/829/2020

ORCID ID:

Z. Levinson

https://orcid.org/0000-0003-

0489-1624

R. Dimitrakopolous

https://orcid.org/0000-00017329-2209

\section{Synopsis}

An innovative strategic mine planning approach was applied to a multi-mine and multi-process gold mining complex that simultaneously considers feasible capital investment alternatives and capacity management decisions. The simultaneous stochastic optimization framework determines the extraction sequence, stockpiling, processing stream, blending, waste management, and capital investment decisions in a single mathematical model. A production schedule branches and adapts to uncertainty based on the likelihood of purchasing a number of feasible investment alternatives that may improve mill throughput or blending, or increase the tailings capacity. Additionally, the mining rate is determined simultaneously by selecting the number of trucks and shovels required to maximize the value of the operation. The mining complex contains several sources - two open-pit gold mines and externally sourced ore - stockpiles, waste dumps, tailings, and three different processing streams. The simultaneous optimization framework integrates the blending of sulphates, carbonates, and organic carbon at the autoclave for refractory ore while managing acid consumption. The production schedule generated branches over an investment in the autoclave expansion; the first branch undertakes a capacity expansion at the autoclave resulting in a $6.4 \%$ increase in NPV, whereas the second branch results in a $27.5 \%$ increase in NPV without the investment. The adaptive approach is compared to a base case production schedule generated using a non-branching two-stage stochastic integer program.

\section{Keywords}

mining complex, simultaneous stochastic optimization, capital investments.

\section{Introduction}

Mining operations are capital-intensive ventures that require smart decisions to strategically time each investment and sustainably produce valuable products. The simultaneous stochastic optimization approach generates an optimal production schedule for a mining complex, using a single mathematical formulation (Del Castillo and Dimitrakopoulos, 2019; Montiel and Dimitrakopoulos, 2015, 2017, 2018; Goodfellow and Dimitrakopoulos, 2016, 2017). The optimized production schedule defines the extraction sequence, stockpiling, processing stream, blending, waste management, and capital investment decisions that maximize the net present value (NPV). These decisions are obtained by considering the interactions throughout the entire mining complex, which may consist of open pit and underground mines, several processing facilities, crushers, stockpiles, and waste destinations (Pimentel, Mateus, and Almeida, 2010). The stochastic approach also manages technical risk during the optimization by integrating a set of stochastic geostatistical simulations of the in-situ material supply, which reproduces the uncertainty and local variability of the material sourced from the mines. Selecting the appropriate time to undertake a capital investment during the life of mine is challenging due to a combination of supply uncertainty, high upfront costs, and prolonged payback periods for each investment. Nevertheless, investments in shovels, trucks, crushers, process plant upgrades, and waste facilities are critical for maximizing the NPV of the long-term production schedule.

The uncertain aspects of mine planning and forecasting, which arise from supply uncertainty, indicate there is large risk in undertaking capital investments (Ajaka, Lilford, and Topal 2018; Asad and Dimitrakopoulos, 2013; Del Castillo and Dimitrakopoulos, 2014; Dowd, 1994; Githiria and Musingwini, 2019; Khan and Asad, 2019; Groeneveld and Topal, 2011; Dimitrakopoulos, 2018; Groeneveld, Topal, and Leenders, 2012; Mai et al. 2018; Ravenscroft, 1992). In particular, supply uncertainty makes it challenging to produce an optimized production schedule with an investment plan that will satisfy the various futures that may unfold. The optimal investment decision for one future outcome may be very 


\section{Adaptive simultaneous stochastic optimization of a gold mining complex: A case study}

different from another scenario. This gives rise to an interest in developing strategic mine plans that can adapt to uncertainty by considering feasible investment alternatives that directly impact the production rate of certain components in the mining complex and manage technical risk.

Del Castillo and Dimitrakopoulos (2019) present an adaptive simultaneous stochastic optimization approach that considers a number of feasible investment alternatives and determines the optimal time to branch the production schedule in order to manage the potential risk of supply uncertainty. A set of orebody simulations is generated for each mine to quantify supply uncertainty. Then, an adaptive approach considers the probability of undertaking an investment in different groups of scenarios. If the decision is counterbalancing, where a representative group of simulations takes on an investment and another representative group does not, the production schedule splits or branches into alternative mine plans based on these investments. Each of these branching alternatives is fully optimized based on the investment that is undertaken; however, decisions made prior to the investment cannot be changed once branching occurs. This prevents the optimization model from anticipating the investment decisions and changing the decisions that were made prior to choosing to invest, as the future investment choices remain uncertain until they are executed.

The adaptive optimization approach integrates nonanticipativity constraints into the optimization formulation. The non-anticipativity constraints ensure that the same decisions are taken unless there is an investment alternative that branches the mine production schedule. If branching occurs, the resulting mine plan of each branch should be distinguishably different based on the investment choice. Otherwise, the non-anticipativity constraints are enforced and the same decision is taken over all the simulated scenarios. The single production schedule generated with feasible investment alternatives provides an advanced method for determining the optimal time to invest and identifies the risk of investing in new equipment, plant improvements, and other infrastructure purchases (Dixit and Pindyck, 1994). Evaluating feasible alternatives and the resulting mine plan creates opportunities to delay, pre-plan, or undertake sizeable capital investments (De Neufville and Scholtes, 2011).

Boland, Dumitrescu, and Froyland (2008) also incorporate non-anticipativity constraints in a multistage optimization framework; however, this approach differs from the adaptive approach described above by Del Castillo and Dimitrakopoulos (2019). In the approach described by Boland and Dimitrakopoulos (2009), the simulated orebody scenarios are differentiated based on the spatial distribution of metal grades, which results in overfitting the production schedule to generate one mine plan per simulated orebody scenario. This method does not lead to an optimal production schedule, given that a single scenario does not represent the uncertainty and local grade variability of the deposit, thus resulting in erroneous production and financial forecasts that misrepresent reality. In contrast, in the case study presented herein, the adaptive approach leverages the ability to branch over several capital investments instead of each block's simulated grades, leading to a practical production schedule with feasible investment alternatives.

Similar multistage frameworks have been applied to strategically time the purchase of capital investments and expand the production capacity in other industries (Ahmed, King, and Parija, 2003; Gupta and Grossmann, 2017; Li et al., 2008;
Singh, Philpott, and Wood, 2009). These frameworks remain impractical for mine planning and design purposes as multistage frameworks lead to a production schedule with one plan per scenario, which misrepresents the ability to change capacities and is the major limitation of multistage approaches. Furthermore, when considering the execution of the long-term production schedule, operations cannot proceed without fixed guidance for the current year of production. Groeneveld, Topal, and Leenders (2012) suggest fixing the initial years of the mine production schedule to address this limitation, ensuring that operations have the appropriate production guidance and lead time to consider different mining and plant options for the future.

The adaptive simultaneous stochastic optimization approach manages technical risk and delivers a mine production schedule that can identify synergies between different components of the mining complex. For example, in a Nevada-type gold mining complex, the metal recovery from refractory ore is influenced by the sulphate and carbonate contents in the material that is delivered to an autoclave processing facility (Montiel and Dimitrakopoulos, 2018; Thomas and Pearson, 2016). Blending the material from several sources in the mining complex to maximize recovery may lead to a higher NPV over the operating life and capture value that is unidentifiable using traditional sequential optimization methods (Gershon, 1983; Hustrulid and Kutcha, 2006; Whittle, 1999). Additionally, waste management considerations such as the production of acid-generating waste and tailings can be integrated into the optimization to minimize detrimental environmental consequences and ensure permitting constraints are satisfied (Levinson and Dimitrakopoulos, 2019; Saliba and Dimitrakopoulos, 2018). These advances are achieved by maximizing the value of the products sold (Goodfellow and Dimitrakopoulos, 2017; Montiel and Dimitrakopoulos, 2015), instead of the traditional approach that considers the economic value of a block determined a priori and sequentially optimizes the extraction sequence, cut-off grade and transportation of materials downstream (Hustrulid and Kutcha, 2006).

Furthermore, the proceeding case study strategically determines the optimal production rate during the mine production scheduling process using an adaptive simultaneous stochastic optimization. Several frameworks directly integrate investments into the optimization to achieve a certain level of production and increase the value of the operation (Goodfellow, 2014; Groeneveld and Topal, 2011; Groeneveld, Topal, and Leenders, 2012). These integrative frameworks allows the optimizer to decide the most suitable time to invest in capital investment, overcoming limitations of defining the optimal mining and processing rates prior to optimizing the production schedule (Del Castillo and Dimitrakopoulos, 2014; Godoy and Dimitrakopoulos, 2004).

This work presents a major case study of a multi-mine and multi-process gold mining complex, where an adaptive simultaneous stochastic optimization approach strategically considers investment alternatives. The main contribution of this study is the ability to simultaneously consider investments in process plant upgrades and the tailings management area, while allowing the model to adapt to uncertainty based on the corresponding investment decisions. In the following sections, the adaptive simultaneous stochastic optimization approach is outlined, followed by a comprehensive case study at a gold mining complex containing two open-pit mines, twelve material types, twelve stockpiles, three external sources (including an 


\section{Adaptive simultaneous stochastic optimization of a gold mining complex: A case study}

underground mine), and three processing stream alternatives. Subsequently, the conclusions and recommendations for future work are presented.

\section{Method}

This section summarizes the method used for the adaptive simultaneous stochastic optimization approach proposed by Del Castillo and Dimitrakopoulos (2019), which allows the production schedule to branch on a set of feasible investment alternatives. All sets, parameters, and decision variables are defined in the following subsections and can be reviewed in Appendix A.

\section{Definitions and notation}

A mining complex is designed to include a set of open pit and underground mines $(M)$, stockpiles $(S)$, processors $(P)$, and waste facilities $(W)$ (Goodfellow and Dimitrakopoulos, 2016, 2017; Montiel and Dimitrakopoulos, 2015, 2017, 2018). There can be many material types that are either extracted from the mine or generated through blending and processing. Each material has a set of attributes which can be transferred through the mining complex (i.e. mass, metal content, etc.). Attributes are further divided into two sub-categories; primary attributes that define the composition of the material passed between various locations in the mining complex, and hereditary attributes which are a derived through linear and nonlinear expressions. Hereditary attributes track important information in the model, including the costs incurred at different locations, revenues from the various processing streams, and metal grade. Two variables $v_{p, i, t, s}$ and $v_{h, t, s}$, quantify the value of primary $(p \in \mathrm{P})$ and hereditary $(h \in$ $\mathrm{H})$ attributes at each location $i \in M \cup S \cup P \cup W$ in period $t \in$ $\mathrm{T}$ under scenario $S \in \mathrm{S}$, respectively. Hereditary attributes allow both nonlinear and linear functions to be incorporated into the model and are a function of the primary attributes, $f_{h}(p, i, k)$ for each primary attribute $p \in \mathrm{P}$ at location $i \in M \cup S \cup P \cup W$ and considering each available capital investment $k \in K$. The primary source of material for the mining complex is obtained by extracting a set of mining blocks $b \in B_{m}$ from mine $m \in \mathrm{M}$. Every block $b$ has a set of simulated primary attributes $\beta_{p, b, s}$ (Goovaerts, 1997; Boucher and Dimitrakopoulos, 2009) which are inputs into the optimization model. The recovery of each attribute $p$ at location $\mathrm{i} \in \mathrm{P}$ in each scenario $s$ is defined as $r_{p, i t s}$ and is calculated using a nonlinear recovery function (Del Castillo, 2018; Farmer, 2016; Goodfellow, 2014).

\section{Decision variables}

Considering a life-of-mine of $\mathrm{T}$ time periods, the adaptive simultaneous stochastic optimization approach aims to maximize the NPV of a mining complex and minimize deviations from the annual production targets. This is accomplished by simultaneously determining the optimal decisions for four decision variables: (i) the mining block extraction sequence, (ii) destination policy, (iii) processing stream, and (iv) capital investment decisions. The method uses a set of binary decision variables $x_{b, t, s}$ that denote whether a block $b$ is extracted in period $t$, in simulation $s$. The destination policy is then defined by discretizing the range of metal grades into a set of bins to determine the cut-off grade policy during the optimization process (Menabde et al., 2007). Bins or groups $g \in G$ are defined using $\mathrm{k}$-means++ clustering algorithm for the primary block attributes $\beta_{p, b, s} \forall p^{\prime} \subseteq \mathrm{P}, \mathrm{b} \in \mathrm{B}_{m}, m \in \mathrm{M}, s \in \mathrm{S}$ of each material type (Goodfellow and Dimitrakopoulos, 2016). The destination policy decision variable $z_{g j, t, s} \in\{0,1\}$ determines if the blocks in group $g$ are sent to destination $j \in O(g)$ in period $t$, where $O(g)$ is the set of locations where the group of materials can be delivered in scenario $S$. After the material reaches the first set of destinations, based on the extraction sequence decisions, the downstream material flow is controlled by the processing stream decision variables $y_{i, j, t,} \in[0,1]$. The processing stream variable defines the portion of product that is sent from destination $i \in S$ $\cup P$ to destination $j \in O(i) \subseteq S \cup P$ in period $t \in \mathrm{T}$ and scenario $S$ $\in \mathrm{S}$. Lastly, the capital investment decision variable $\omega_{k, s, t}$ defines whether a capital investment $k \in K$ is executed in period $t \in \mathrm{T}$ and scenario $s \in \mathrm{S}$. This is explained more fully in the following section.

\section{Branching the production schedule}

Two different sets are used to describe the different types of investments: branching $\left(K^{*}\right)$ and non-branching $\left(K^{=}\right)$, where $K^{*}$ $\cup K^{=}=\mathrm{K}$. Branching alternatives are large capital investment decisions that are made only once during the life of the mining complex, for example, purchasing large crushers or constructing a new tailings facility. The non-branching investments may occur multiple times over the planning horizon, for instance truck and shovel purchases. The decision tree outlines the optimal timing of the branching investments and a new node $n$ is created for each branching decision; this is defined as a stage. An optimized mine plan is produced for each branch that is created. The representative measure $R \in(0,0.5)$ is a user-defined parameter, which is used to describe the confidence interval for branching. $R$ defines the probability threshold required to invest over all scenarios, branch the production schedule, or not invest in each capital investment (Equation [1]).

$$
\left\{\begin{array}{l}
\text { if the probability of investing in } k^{*}<R \rightarrow \text { do not invest in } k^{*} \text { during } t^{\omega} \\
\text { if probability of investing in } k^{*} \in[R, 1-R] \rightarrow \text { branch during } t^{\omega} \\
\text { if the probability of investing in } k^{*}>1-R \rightarrow \text { invest in } k^{*} \text { during } t^{\omega}
\end{array}\right.
$$

The branching mechanism is described in the subsequent steps:

- Calculate the probability of investing in all alternatives $k^{*} \in$ $K^{*}$ in each time period $t$.

$>$ If there are a representative number of scenarios that choose to purchase the investment alternative, within an allotted time window, the solution branches and a new stage is created. However, if the probability of investing is less than the threshold then the optimization will not branch, and the investment is not purchased. On the contrary, if the probability is greater than $(1-R)$ there is no branching and the investment is made over all scenarios. This is mathematically described in Equation [1].

- Given there are $\mathrm{S}_{n} \subseteq \mathrm{S}$ scenarios that belong to the root, these scenarios are partitioned into $S_{n 1}$ and $S_{n 2}$ when branching occurs. Therefore, when combined all the simulations from each branch are at the root $\left(\mathrm{S}_{n 1} \cup \mathrm{S}_{n 2}=\mathrm{S}_{n}\right)$, and when the simulations are partitioned each simulation can only report to one of the two partitions $\left(\mathrm{S}_{n 1} \cap \mathrm{S}_{n 2}=\varnothing\right)$.

A time window, $\tau_{\omega}=\{t-\omega, t+\omega\}$, is used to stabilize the solution as often there may be a representative number of scenarios between one or two consecutive periods, making it more desirable to invest in one of those two years rather than completely ignore the investment opportunity. $\omega$ is set as an integer value that allows the model to expand the time window 


\section{Adaptive simultaneous stochastic optimization of a gold mining complex: A case study}

of the branching mechanism. The branching or new stage will begin during the floor of the expected time period of investment $k^{*}$ and is denoted as $t^{*}$. Lastly, $N$ defines the minimum number of scenarios in a branch required to allow for further branching in periods $t+1 \in \mathrm{T}$.

\section{Capital investments}

Capital investments are critical decisions that require a lead time $\left(\tau_{k}\right)$ to assemble or construct. For each investment alternative $k \in \mathrm{K}$ there is a life expectancy $\left(\lambda_{k}\right)$ and a unitary increase in capacity $\left(\kappa_{k, h}\right)$ that comes at a discounted purchase cost $\left(p_{k, t}^{K}\right)$ for each period $t \in \mathrm{T}$. The periodicity $\left(\psi_{k}\right)$ of the investment decisions is also incorporated into the optimization model to simplify the optimization process and ensure a practical plan. The number of investments undertaken is denoted by $\sigma_{k, t, s}$ for each investment $k$ $\in \mathrm{K}$ in period $t \in \mathrm{T}$ and scenario $s \in \mathrm{S}$.

\section{Objective function and constraints}

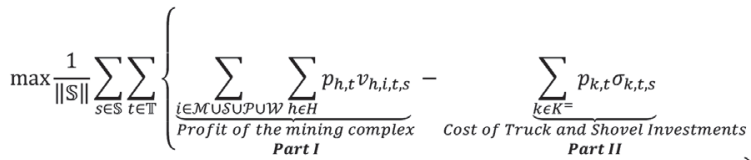

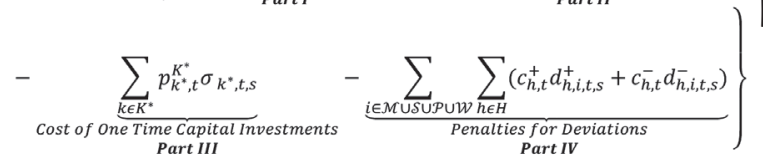

The objective function (Equation [2]) maximizes the expected profit obtained by summing the revenues generated from the metal produced and subtracting the various costs, for example, transportation, mining, processing, and refining costs (Part I). In addition, the objective aims to minimize the costs of investing in trucks and shovels (Part II), and one-time capital investments (Part III). Part IV minimizes the deviation from production targets, actively managing uncertainty. The adaptive optimization approach will purchase investments only when they lead to an increase in overall profitability and/or improve the capability to meet production targets in the mining complex.

Integrating the feasible investment alternatives into the optimization model changes the standard formulation of capacity constraints, from static upper $\left(U_{h, i, t}\right)$ and lower $\left(L_{h, i, t}\right)$ bounds in Equations [3] and [4], respectively, to dynamically changing capacities that are determined during the optimization. The capacities reflect changes in the corresponding investment decisions $\omega_{k, s, t} \kappa_{k, h}$ represents the unitary increase in production capacity:

$$
\begin{aligned}
& v_{h, i, t, s}-d_{h, i, t, s}^{+} \leq U_{h, i, t}+\sum_{k \in K ; t>\tau_{k}} \sum_{t^{\prime}=t-\lambda_{k}-\tau_{k}}^{t-\tau_{k}} \kappa_{k, h} \cdot \omega_{k, s, t^{\prime}} \text { [3] } \\
& v_{h, i, t, s}-d_{h, i, t, s}^{-} \leq L_{h, i, t}+\sum_{k \in K ; t>\tau_{k}} \sum_{t^{\prime}=t-\lambda_{k}-\tau_{k}}^{t-\tau_{k}} \kappa_{k, h} \cdot \omega_{k, s, t^{\prime}} \text { [4] } \\
& \forall h \in H, i \in \mathcal{M} \cup \mathcal{S} \cup \mathcal{P} \cup \mathcal{W}, t \in \mathbb{T}, s \in \mathbb{S}, k \in K \\
& d_{h, i, t, s}^{+}, d_{h, i, t, s}^{-} \geq 0
\end{aligned}
$$

When investments are activated the capacity expansions and contractions can be explored, allowing for changes to the extraction rate, processing capacity, and storage of waste materials.
In addition, non-anticipativity constraints (Equations. [7], [8], and [9]) ensure that all scenarios within the same branch undertake the same decisions. The problem is initialized with the solution from a two-stage stochastic integer program and then non-anticaptivity constraints are enforced for the first period. Subsequently, the mechanism for branching iteratively solves a series of sub-problems to determine the optimal period to invest The non-anticipativity constraints are then dynamically enforced over an iteratively increasing time frame $T^{\alpha}$ when a branching investment is undertaken. For example, once the first branching period is established non-anticipativity constraints become active for all periods up to $t^{*}$, the period in which a branching investment is undertaken. This ensures that the optimization framework will not change earlier decisions in anticipation of the investments made in future periods. A binary variable $u_{k}^{n}{ }^{*}, t$ equals unity when the design branches over option $k^{*} \in K^{*}$ in node $\mathrm{n}$ in period $t \in \mathrm{T}$ and zero otherwise. Therefore, the variable $A$ determines whether the non-anticipativity constraints are activated $(0)$ or not (1) for a given partition of scenarios in a single branch:

$$
A=\left\lceil\frac{\sum_{k^{*} \in K^{*}} u_{k^{*}, t}^{n}}{\left|K^{*}\right|}\right\rceil=\{0,1\}
$$

When there is no branching all decision variables must be the same for all scenarios. However, when branching occurs the scenarios partition $\mathrm{S}_{n 1}=\left\{s: w_{k^{*}, t^{*}, s}=1, \forall s \in \mathrm{S} n\right\}, \mathrm{S}_{n 2}=\mathrm{S}_{n} \backslash \mathrm{S}_{n 1}$. Examples of the non-anticipativity constraints are given below:

$$
\begin{aligned}
& (1-A)\left(x_{b,(t+1), s}-x_{b,(t+1), s^{\prime}}\right)=0, \quad \forall t \in T^{\alpha} ; b \in M \\
& (1-A)\left(z_{g, j,(t+1), s}-z_{g, j,(t+1), s^{\prime}}\right)=0, \\
& \forall t \in T^{\alpha} ; g \in G ; j \in \mathcal{M} \cup \mathcal{S} \cup \mathcal{P} \cup \mathcal{W} \\
& (1-A)\left(w_{k,(t+1), s}-w_{k,(t+1), s^{\prime}}\right)=0, \quad \forall t \in T^{\alpha} ; k \in K
\end{aligned}
$$

The destination policy, extraction sequence, and capital investment decisions are the same for all scenarios within each branch of the decision tree. Lastly, in order to ensure stochastic solution stability there must be a minimum number of simulated scenarios in each partition.

\section{Solution method}

A multi-neighbourhood simulated annealing metaheuristic is used to solve the optimization model. Metaheuristics are required as the number of decision variables is in the order of hundreds of millions when considering a multi-mine, longterm production schedule. The metaheuristic used in this work explores a neighbourhood or class of perturbations that are used to change decision variables and arrive at near-optimal solutions in a short period of time (Goodfellow and Dimitrakopoulos, 2016, 2017; Montiel and Dimitrakopoulos, 2015, 2017). Del Castillo (2018) introduces perturbations that change capital investment decisions, including adding or removing multiple investments in a period and swapping two investments between periods. The simulated annealing algorithm then uses an acceptance probability to determine whether the new solution is accepted or rejected to further explore the solution space (Kirkpatrick, Gelatt and Vecchi, 1983). The modified simulated annealing approach, used in the subsequent case study, updates the probability of choosing a neighbourhood depending on its ability to improve the objective function (Goodfellow and Dimitrakopoulos, 2016). 


\section{Adaptive simultaneous stochastic optimization of a gold mining complex: A case study}

\section{Case study at a gold mining complex}

The adaptive simultaneous stochastic optimization approach is applied to a gold mining complex that consists of two large open-pit mines with twelve different material types. These materials can be transported to a number of destinations: an autoclave processing facility, oxide mill, oxide leach, twelve stockpiles (one for each material type), waste facility, and a tailings management area. Each mine exploits a mixture of sulphide ores, which must be pretreated at the autoclave before processing, and oxide ores that can be sent to the oxide processor or oxide leach. The mining complex, including each of its component, and the allowable material routing, is presented in Figure 1. Sulphide materials, a refractory ore type, can be extracted from either of the open pit mines and sent to the autoclave, stockpile, or waste dump facility. Stockpiles are separated for each material type to provide accessibility to materials of certain chemical compositions, shown in Table I. Material that is sourced externally is used to supplement the ore

\begin{tabular}{|c|c|c|c|c|}
\hline \multicolumn{5}{|c|}{$\begin{array}{l}\text { Table I } \\
\text { Material classification for blending and material routing }\end{array}$} \\
\hline \multirow{2}{*}{\begin{tabular}{|c|} 
Material \\
Type \\
\end{tabular}} & \multicolumn{4}{|c|}{ Chemistry } \\
\hline & $\mathrm{CO}_{3}$ & ss & oc & Oxide \\
\hline 1 & Med-low & Low & - & - \\
\hline 2 & Med-low & High & - & - \\
\hline 3 & Low & Med & - & - \\
\hline 4 & Low & Low & - & - \\
\hline 5 & Low & Med-high & - & - \\
\hline 6 & High & - & - & - \\
\hline 7 & Med-high & Low & - & - \\
\hline 8 & Low & High & - & - \\
\hline 9 & Very high & - & - & - \\
\hline 10 & High & - & Med-high & - \\
\hline 11 & - & - & High & - \\
\hline 12 & - & - & - & High \\
\hline
\end{tabular}

feed that is produced at the two open pit mines and sent to the autoclave to help meet blending requirements. The optimizer seeks opportunities to increase value and more effectively blend materials to obtain a satisfactory product quality for effectively running the autoclave. Sulphide or refractory ores must be blended to achieve the permissible operating criterion for the autoclave, by controlling the grades of sulphide sulphur (SS), carbonate $\left(\mathrm{CO}_{3}\right)$, organic carbon $(\mathrm{OC})$, and the $\mathrm{SS} / \mathrm{CO}_{3}$ ratio. Therefore, these deleterious attributes must be managed within the optimization framework to ensure blending requirements will be met. A constraint is added to the model to maintain the grades of SS and $\mathrm{CO}_{3}$ between $3.8-4.2 \%$ and $4.5-6.5 \%$, respectively. Deviations from these targets are penalized in the objective function to manage the risk similar to all the other production targets. Acid is used to pretreat the ore by neutralizing $\mathrm{CO}_{3}$ and ensuring the appropriate $\mathrm{SS} / \mathrm{CO}_{3}$ ratio (0.8-1.2) enters the autoclave circuit. This becomes critical as there is variability in the material received from the different sources and often there are not enough materials with the desired qualities readily available. There is a maximum amount of acid (38 $400 \mathrm{t}$ ) that can be used on an annual basis, which introduces a constraint in the optimization process. The autoclave's target production is 2.5 Mt/a. Oxide materials can report to either the oxide mill, leach, or stockpile and there are no constraints on the blending requirements for the oxide ore material. The oxide mill has a production target of $1.4 \mathrm{Mt} / \mathrm{a}$ and the leach pad is not constrained. After processing, the volumes of mine tailings that are generated from the processing facilities are continuously examined to ensure there is a large enough containment area to continue processing, which then introduces a constraint on the available tailings capacity. Stockpiling facilities are used as intermediate locations to assist with blending and can be extracted from throughout the mine life. Lastly, any material that does not positively contribute to the NPV of the mining complex is sent to the corresponding waste dump facility.

In this case study, there are three one-time feasible investment alternatives considered throughout the optimization process to test the adaptive optimization approach. First, the annual autoclave processing throughput may be expanded by investing in two additional positive-displacement piston-

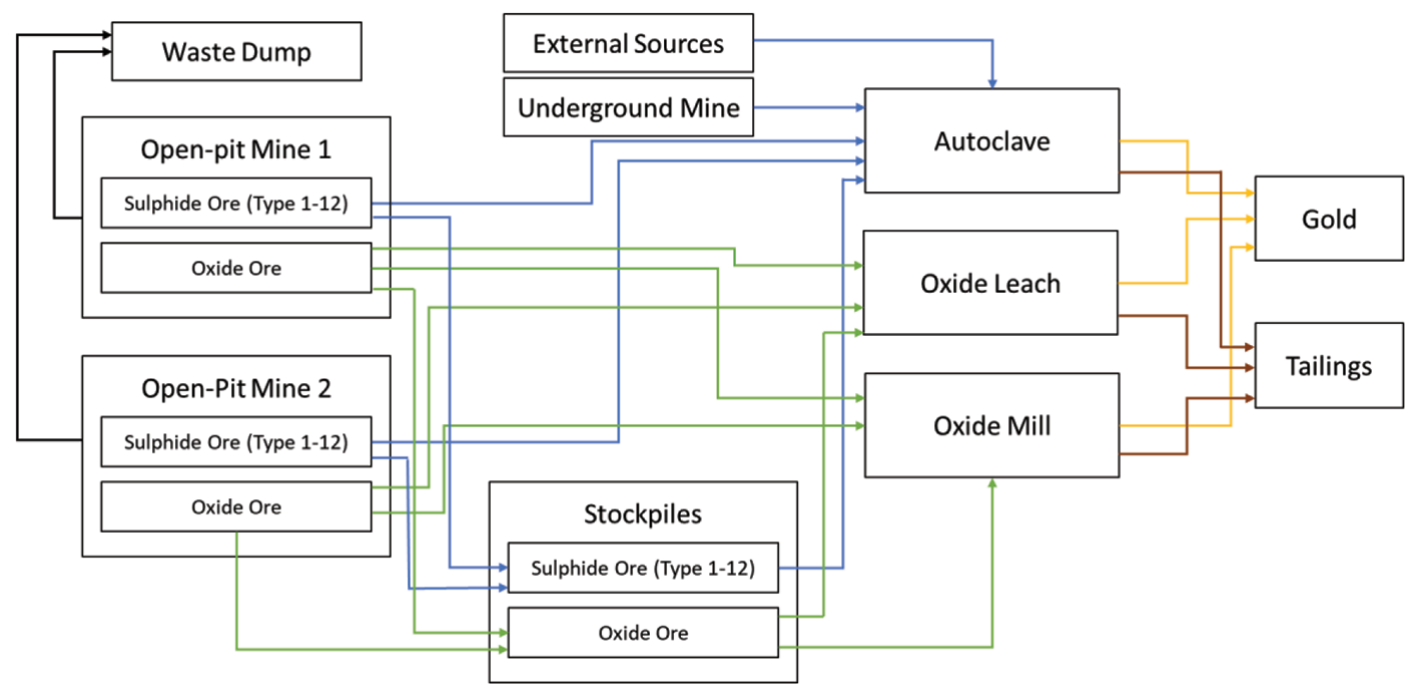

Figure 1-The mining complex and allowable material routing 


\section{Adaptive simultaneous stochastic optimization of a gold mining complex: A case study}

\begin{tabular}{|c|c|c|c|c|c|}
\hline \multirow{2}{*}{ Parameters } & \multicolumn{2}{|c|}{ Non-branching } & \multicolumn{3}{|c|}{ Branching expansions } \\
\hline & Shovel & Truck & Tailings & Autoclave & Acid \\
\hline Lead time (years) & 2 & 2 & 3 & 2 & 3 \\
\hline Capital cost (\$ million) & 10 & 1.6 & 200 & 1 & 0.2 \\
\hline Life of equipment (years) & 7 & 7 & 13 & 13 & 13 \\
\hline Periodicity of decision (years) & 3 & 3 & 13 & 13 & 13 \\
\hline Increase in capacity & Feed for 5 trucks/unit & $1.4 \mathrm{Mt} /$ unit & 5.75 million $\mathrm{m}^{3}$ & $925 \mathrm{kt}$ & $9.6 \mathrm{kt}$ \\
\hline
\end{tabular}

diaphragm pumps (Eichhorn et al., 2014). Secondly, an investment in the process plant autoclave circuit is evaluated to increase the allowable acid consumption and manage blending. Thirdly, an investment alternative that considers the construction of a new tailings storage area to increase the life of mine by allowing the processors to continue operating. The pump installation increases throughput at the autoclave by $25 \%$. which allows for more refractory ore to be processed. The capital cost of this expansion is minimal; however, the cost of implementation and loss of production during the pump installation is also considered in the capital investment decision, resulting in a \$1 million investment. Acid is ordered annually to satisfy production requirements, but storage areas and adaptations to the autoclave pretreatment circuit are required to safely utilize the additional acid. The expected investment is $\$ 0.2$ million. The most significant investment decision is related to the addition of a new tailings containment area, which is expected to cost $\$ 200$ million to construct completely. The new tailings area results in a 33\% increase in tailings storage capacity for the mining complex. Once any of the three investments are purchased, they can be continuously used for the remainder of the mine life. Additionally, these three capital investment decisions can potentially allow the production schedule to branch. In this case study, a representativity measure $R=0.3$ is used based on the acceptable risk of investing in capital at this mining operation. Therefore, the production schedule branches when a representative number of scenarios, between $30 \%$ and $70 \%$, invest in one of these three feasible alternatives. The scenarios are then split, and further branching considerations are assessed in future periods. Further details on the parameters considered for each of the capital investments are described in Table II.

The mine initially begins with 30 haul trucks and six shovels that have two years remaining productive life before salvaging. The model dynamically considers the purchase of trucks and shovels throughout the thirteen-year production schedule. Truck and shovel purchases define the annual mine production rate. The cost per truck and shovel is $\$ 1.6$ million and $\$ 20$ million, respectively, which is accounted for in the annual cash flows, allowing for the optimizer to decide on the appropriate time to invest in trucks and shovels throughout the mine life. The mining operation has an ageing fleet and is planning to replace the originally purchased haul trucks with a new fleet. The ability to consider the purchase of new equipment during the optimization provides an opportunity to re-establish the optimal mining rate to satisfy the processor requirements and maximize the value of the operation. The trucks and shovels have a corresponding lead time of two years to provide a suitable amount of time for purchasing equipment from the manufacturer, shipping, and on-site assembly. In addition, they have an expected equipment life of seven years and a purchase can be made every three years, stabilizing the production rate.

\section{Base case mine production schedule}

A base case mine production schedule is defined here using a simultaneous stochastic optimization approach that considers capital investment decisions within the optimization framework

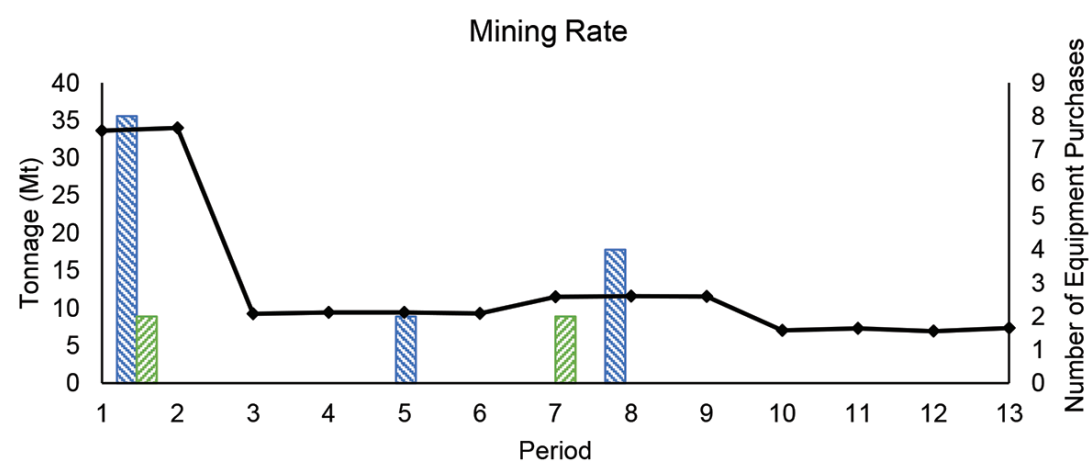

Wruck Purchases $\square$ Shovel Purchases $\longrightarrow$ Base Case - Mine Tonnage

Figure 2-The mining rate and shovel/truck purchase plan for the base case production schedule with no branching 


\section{Adaptive simultaneous stochastic optimization of a gold mining complex: A case study}

while managing uncertainty. Branching, however, is not considered. The base case mine production schedule can choose to invest in trucks, shovels, and the available expansions, but it cannot branch and adapt to uncertainty by considering alternatives; it must choose either to invest or not to invest. This is different from the adaptive simultaneous stochastic optimization that can be used to evaluate different alternatives and their corresponding value, as there is a fixed production schedule that must be executed in one way, which does not consider the value of having alternative options to manage uncertainty to a greater extent. The results from the base case mine production schedule are compared with the adaptive branching approach that considers feasible capital investment alternatives. Each method uses a set of multivariate stochastic simulations of the orebody for each open pit as input to the optimization model (Boucher and Dimitrakopoulos, 2009; Rossi and Deutsch, 2014). The external sources are simulated based on historical data associated with variability in the supply and quality of material received from other mines in the region. The variability and uncertainty of the material sources are accounted for directly in the optimization framework, unlike conventional frameworks that use a single estimated orebody model as input (Hustrulid and Kutcha, 2006). Lastly, the open pit mines have a block size of $30 \mathrm{~m} \times 30 \mathrm{~m} \times 20 \mathrm{~m}$, representing the selective mining unit and contain 296000 and 172000 blocks in Mine 1 and Mine 2, respectively.

The results from the base case production schedule, including the extraction sequence, capital investments, stockpiling, blending, mining rate, and processing decisions, follow. Figure 2 defines the base case mining rate alongside the truck and shovel investment decisions. Noticeably, the amount of equipment that is required decreases as the mine life proceeds and as the older equipment approaches the end of its operational life, an opportunity arises to operate the two mines at a lower mining rate. Although a lower mining rate is utilized, the ability to satisfy the autoclave processor (Figure $3 \mathrm{a}$ ) and oxide mill is fulfilled and a resulting NPV of $\$ 3.65$ billion is achieved in the $50^{\text {th }}$ percentile $(\mathrm{P}-50)$. The base case mine production schedule invests in both the expansion of the tailings management area and the additional acid storage facility. The investment in additional pumps does not contribute an increase to the mining complex's NPV when accounting for all scenarios, consequently the pumps are not purchased. The blending constraints are satisfied, between the upper (UB) and lower bounds (LB), in most years through the utilization of stockpiles and other available material (Figure 3b, 3c). However, during the first year, the blending constraints are unachievable as the material that can be extracted during that year does not have the appropriate properties to meet the blending requirements. As the production schedule proceeds, stockpiles are established to help with blending in future years. The operational costs of stockpiling these materials are integrated into the optimization to ensure that the stockpiling decisions contribute to the profitability of the mining complex and help manage the technical risk.

Lastly, the base case production schedule invests in a tailings storage expansion in year 7 . This investment increases the

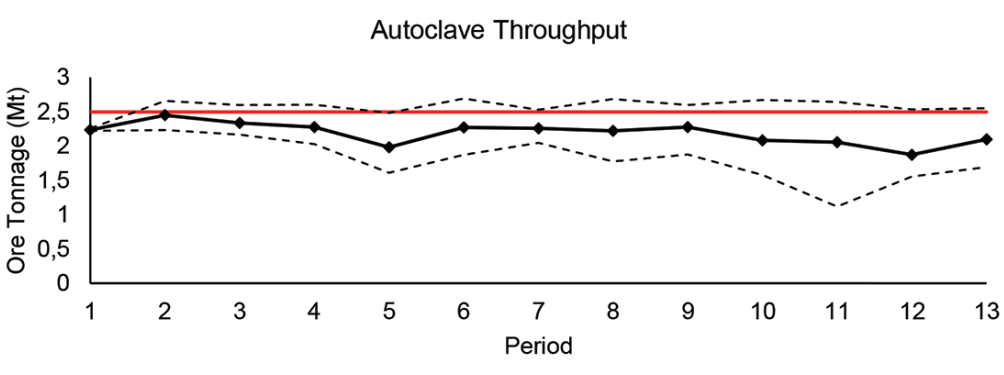

Sulphide Sulphur Blending

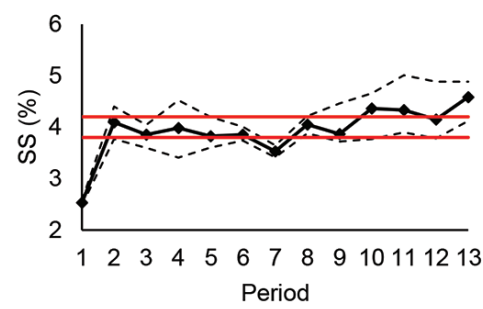

Carbonate Blending

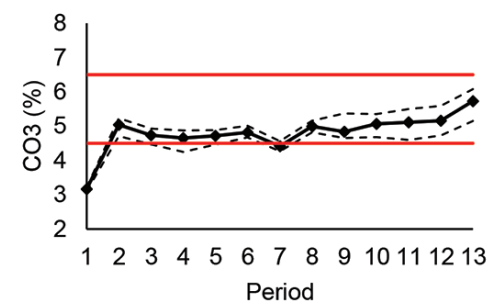

SS/CO3 Ratio

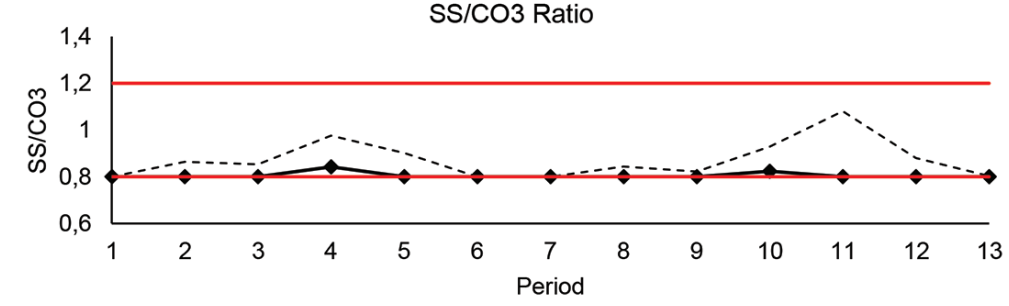

- - - Base Case - P10 - Base Case - P50 - - - Base Case - P90 $\longrightarrow$ UB $\longrightarrow$ LB

Figure 3-Base case autoclave throughput and blending: (a) no expansion taken in the optimization for additional throughput, (b) blending of SS, (c) blending of CO3, (d) maintaining the SS/CO3 ratio for ideal operating conditions 


\section{Adaptive simultaneous stochastic optimization of a gold mining complex: A case study}

Tailings Volume

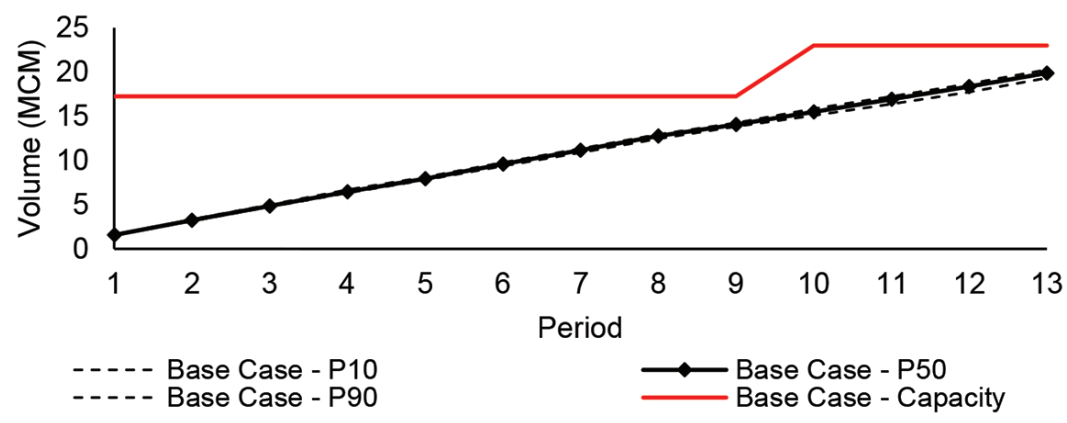

Figure 4-Tailings production over the long-term production schedule and the available capacity expanded in year 10

storage capacity and becomes available in year 10 (Figure 4). The increased tailings storage prolongs the mine life by three years and allows for 1 to 2 more years of gold production if the duration of this schedule is increased. This results in an additional $\$ 0.7$ billion in discounted cash flows generated. It is important to optimize waste management considerations, such as tailings disposal, directly in the mine production scheduling process in order to generate feasible life-of-mine designs. Additionally, the processor upgrade that allows for additional acid consumption was purchased in year 3 , allowing for a $20 \%$ increase in acid consumption in subsequent years Figure 5). This controls the blending requirements at the autoclave processing stream.

\section{Adapting to supply uncertainty in a gold mining complex}

The previously discussed results will be compared with the adaptive stochastic optimization that considers branching on feasible capital alternatives. During the adaptive simultaneous stochastic optimization, groups of scenarios are optimized to determine if there is a beneficial time to invest in any of the onetime capital investments alternatives described previously. The scenarios that lead to a branching decision are separated based on those that invest and those that choose not to invest in the time window. The scenarios that choose not to invest maintain the ability to invest in the capital investment in future years, while the scenarios that invest lock in that decision for that year, activating the non-anticipativity constraints. The scenarios are grouped into separate branches and optimized to produce a feasible alternative for both investing and not investing in the solution. A representative number (over 30\%) of scenarios must undertake the same decision for the solution to consider branching or investing in these alternatives, which reduces the number of branches and prevents overfitting the decision tree to each scenario. It is important to note that the scenarios in each branch all undertake the same decisions until a new branching decision is made.

Based on the available capital investments, it was first determined that the additional acid capacity was a suitable investment for more than $70 \%$ of the scenarios leading to a non-branching investment decision. The first investment helped improve the ability to meet the quality requirements of the autoclave. After considering all the simulated scenarios (geostatistical simulations of each open pit mine and an uncertain external source) and the branching mechanisms criterion, the first branching decision is undertaken, allowing for the expansion of the autoclave throughput by installing two additional positivedisplacement pumps. This separates the number of scenarios into a group of 115 scenarios in branch 1 (B1) that invest and 205 scenarios in branch 2 (B2) that do not invest. After the branching occurs, the optimizer also decides to invest in the additional tailings capacity in more than $70 \%$ of the scenarios, for both branches, preventing further growth of the scenario tree. The resulting feasible alternatives both produce a higher NPV than the base case production schedule, achieving a value of $\$ 3.89$ billion in B1 and $\$ 4.66$ billion in B2 (Figure 6). This accounts for a $6.4 \%$ and $27.5 \%$ increase in NPV when comparing the P-50 of each alternative to the base case production schedule. Each of the branches or feasible alternatives performs better than the base case production schedule; however, this may not always be the case as there could be a group of scenarios that underperforms the base case production schedule. The method prevents overfitting by ensuring that the number of scenarios

\section{Acid Consumption}

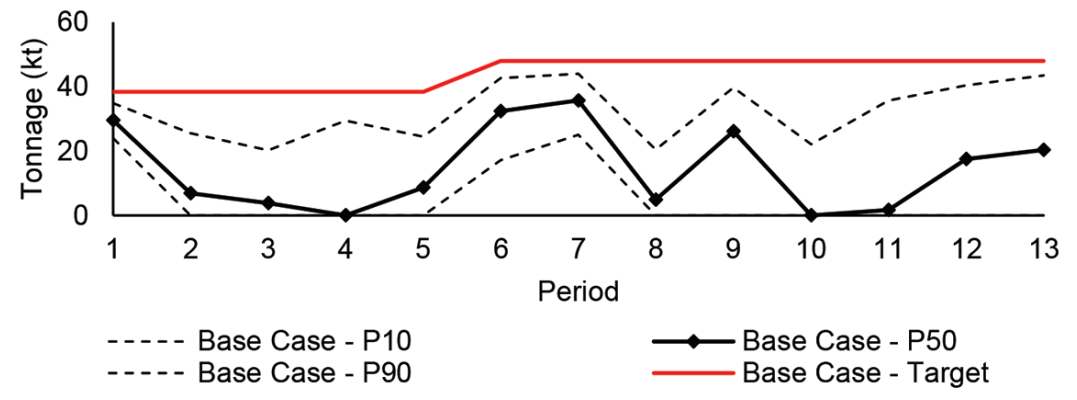

Figure 5-Annual acid consumption with additional capacity obtained in year 6 


\section{Adaptive simultaneous stochastic optimization of a gold mining complex: A case study}

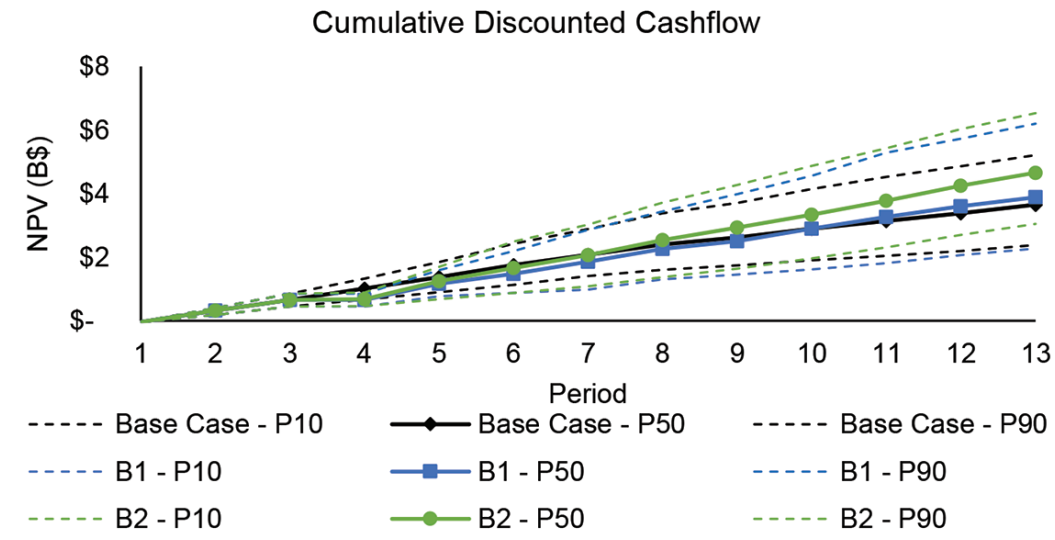

Figure 6-Comparison of the NPVs from the adaptive branching and base case production schedule

does not become too few within each branch and that there is a significant difference in the number of scenarios that either invest or maintain the same operating conditions, hence the representativity parameter which ensures between $30 \%$ and $70 \%$ of the scenarios will be split and not a small group of outliers. This substantially reduces the number of branches and ensures feasible, stable solutions. The changes in the investment decisions result in very different responses in the production scheduling process, as shown in Figure 7, when comparing the N-S cross-sections. The solution is exactly the same until branching occurs, and then the schedules change dramatically to take advantage of the new capital investments. There are a number of similarities between the base case and B2 in terms of the depth and extent of the mine. However, in B1 there is a large area in the north of the mine where extraction no longer occurs, compared to the other two mine plans. This implies that there is some high material variability and uncertainty in this section of the mine, which leads to large changes in the resulting mine plan.

B1 invests in the autoclave expansion (Figure 8), which can be fully utilized in year 6 , and has the lowest mining rate over the long-term production schedule. A comparison of the mining rates is given in Figure 9, where the resulting production rates directly correlate to the number of trucks and shovels purchased. The autoclave expansion results in lower grade refractory ore material being processed and a higher throughput at the autoclave. Over the long-term production schedule, there is a $9 \%$ reduction in the number of gold ounces produced over the life of mine compared with the P-50 of the base case scenario. However, the reduction in mining costs due to the lower mining rate overcompensates the loss in revenue and results in a higher NPV. The lower mining rate is feasible as the throughput outweighs the grade of material through the autoclave, changing the
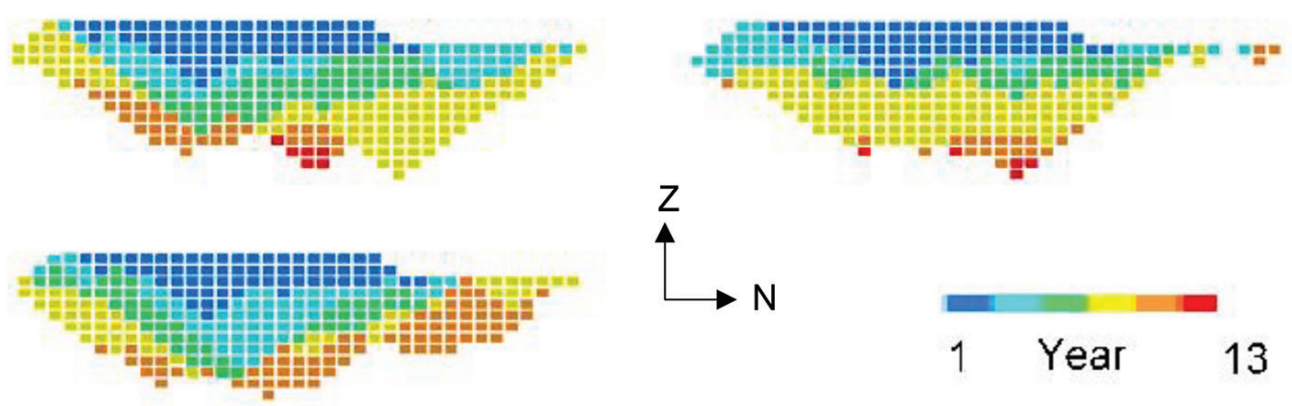

Figure 7-N-S cross-section of production schedule Mine 1: (a) base case (top left), (b) branch 1 (top right), and (c) branch 2 (bottom left)
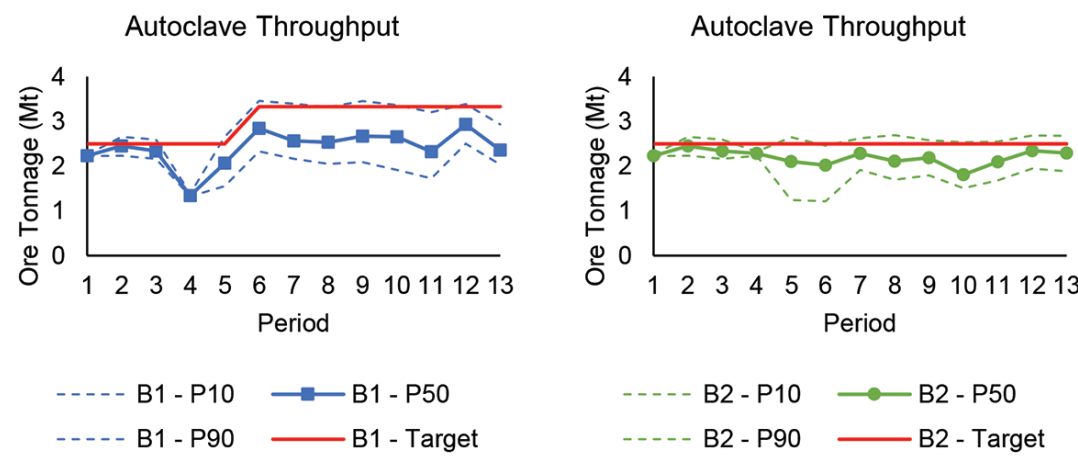

Figure 8-Autoclave throughput and targets (a) B1 and (b) B2 with investments 


\section{Adaptive simultaneous stochastic optimization of a gold mining complex: A case study}

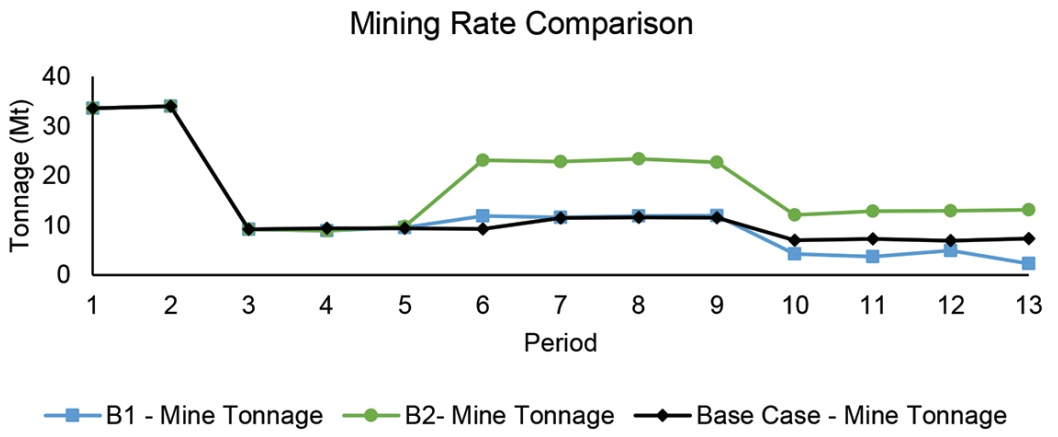

Figure 9-A comparison of the mining rates required to satisfy each production schedule

selectivity between ore and waste material. Lower utilization of the oxide processing facilities also decreases the operating costs. In B1, the optimizer has a challenging time meeting the blending constraints and is unable to provide the appropriate material to attain the blending targets, making the acid investment a critical decision for ensuring there is a suitable $\mathrm{SS} / \mathrm{CO}_{3}$ ratio.

B2 performs quite differently and instead increases the size of the truck and shovel fleet, which results in a higher extraction rate and ensures that higher-grade refractory ore is sent to the processor. The oxide processing streams are utilized far more in B2 than in B1 and their target production is maintained during most years. A higher stripping ratio is required to move the additional waste between years 5 and 9 (Figure 10), which is the reason for the additional truck and shovel requirements. Increasing the selectivity between ore and waste results in a substantially higher NPV, which B1 was unable to achieve even with the autoclave capacity expansion. The larger contribution in NPV is primarily due to the accessibility of oxide materials in the different groups of simulations and the uncertainty and variability in the gold, $\mathrm{SS}, \mathrm{CO}_{3}$, and $\mathrm{OC}$ grades. Here the adaptive approach is able to take advantage of understanding the inherent variability of the mineral deposits and indicates that there is an important investigation to be conducted. This includes more information with regards to the mineralization of oxide materials and stricter guidelines in terms of the quality of material received from external sources before deciding on the autoclave expansion. B2 produces 10\% more gold by fully utilizing all the processing stream capacities and better satisfying the blending constraints. The increased utilization of the oxide leach and mill contribute significantly more gold ounces.

Total Waste Production

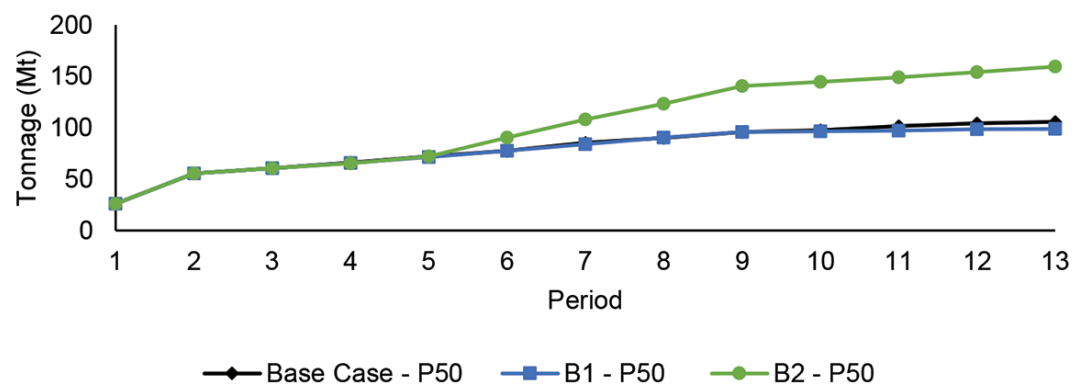

Figure 10-Total waste production over the long-term production schedule

Tailings Volume

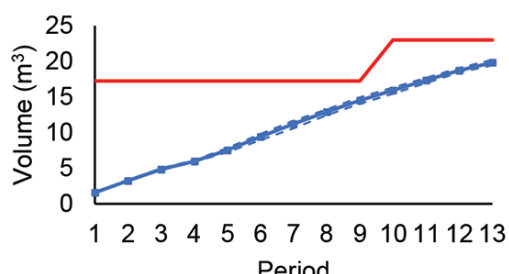

Period

$$
\begin{aligned}
& -\mathrm{B} 1 \text { - P10 } \longrightarrow \text { B1 - P50 } \\
& -\mathrm{B} 1 \text { - Target }
\end{aligned}
$$

Tailings Volume

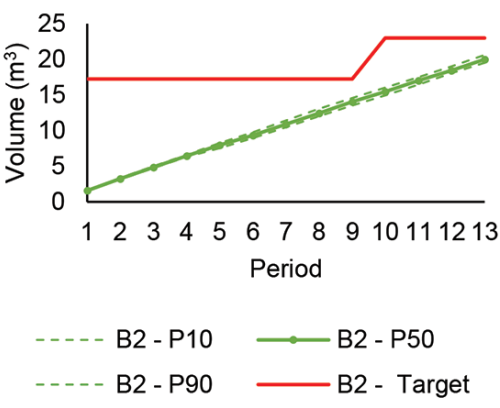

Figure 11-Total tailings production with investment decisions 


\section{Adaptive simultaneous stochastic optimization of a gold mining complex: A case study}

The feasible alternatives B1 and B2 invest in the additional tailings containment area in year 7 and receive the capacity in year 10, similar to the base case. Had the tailings expansion not been considered during the optimization process, processing would have been required to stop in year 10 and a loss of $\$ 1$ billion and $\$ 1.3$ billion in additional cash flow would be incurred in B1 and B2, respectively. This would be a larger loss than the resulting $\$ 0.7$ billion in the base case production schedule. The potential loss highlights the importance of simultaneously optimizing the entire mining complex to further understand the intrinsic value of each investment decision.

\section{Conclusions}

The simultaneous stochastic optimization of a gold mining complex was studied using an adaptive method that integrates feasible capital investment alternatives. The framework capitalizes on synergies and adapts to uncertainty, resulting in a $6.4 \%$ and $27.5 \%$ increase in NPV in branch 1 (B1) and branch 2 (B2) respectively, while satisfying a wide array of production targets and managing supply uncertainty. Investments in trucks and shovels define a new mining rate that minimizes capital expenditure and satisfies each processor's capacity. Additionally, an investment in a tailings facility expansion and additional acid consumption increase the life of the mining complex and manage variable material quality at the autoclave processor. Integrating tailings management into the optimization process increases the NPV by $\$ 0.7$ billion in the base case production schedule and leads to an additional $\$ 1$ billion in B1 and $\$ 1.3$ billion in B2. This emphasizes the importance of considering waste and tailings management in the optimization process in order to capitalize on the available synergies. The optimizer chooses to branch the production schedule when the autoclave expansion is considered and identifies uncertainty and local variability associated with the supply of oxide and refractory ores sent to each processor. This leads to different mine plans and operating requirements for the processing streams and mining equipment, depending on whether the investment alternative is purchased. The feasible investment alternatives provide a high level of insight into the appropriate attributes to investigate, including highly variable areas of the deposit and large differences in the quantity of oxide materials mined. The optimized production schedule does not branch for the first three years and provides the appropriate lead time to evaluate each alternative decision and gather the required information to construct an informed final production schedule.

If either of the feasible alternatives are executed, the expected NPV increases substantially. The base case and adaptive approaches capitalize on the synergies that exist between the different components of the mining complex, helping to manage the challenging blending constraints and determine the appropriate size of the mining fleet directly in the optimization. The results from this case study emphasise the importance of modelling the entire mining complex in a single optimization process. In addition, the branching mechanism and adaptive ability of the optimizer provides a method to easily evaluate several feasible alternatives and further understand the variability and uncertainty associated with the mining complex.

\section{Acknowledgements}

This work is funded by the National Science and Engineering Research Council of Canada (NSERC) CRD Grant 500414-16, NSERC Discovery Grant 239019, the COSMO Stochastic Mine Planning Laboratory and mining industry consortium (AngloGold
Ashanti, Barrick Gold, BHP, De Beers, IAMGOLD, Kinross, Newmont Mining, and Vale), and the Canada Research Chairs Program.

\section{References}

AJAKA, A.D., LILFord, E., and Topal, E. 2018. Application of predictive data mining to create mine plan flexibility in the face of geological uncertainty. Resources Policy, vol. 55. pp. 62-79 https://www.doi.org/10.1016/j.resourpol.2017.10.016

Ahmed, S., King, A.J., and PariJA, G. 2003. A multi-stage stochastic integer programming approach for capacity expansion under uncertainty. Journal of Global Optimization, vol. 26. pp. 3-24. https://doi.org/https://doi.org/10.1023/A:1023062915106

AsAd, M.W.A., and Dimitrakopoulos, R. 2013. Implementing a parametric maximum flow algorithm for optimal open pit mine design under uncertain supply and demand. Journal of the Operational Research Society, vol. 64, no. 2. pp. 185-197. https://doi.org/10.1057/jors.2012.26

Boland, N., Dumitrescu, I., and Froyland, G. 2008. A multistage stochastic programming approach to open pit mine production scheduling with uncertain geology. Optimization Online. http://www.optimization-online.org/DB_FILE/2008/10/2123.pdf

Boucher, A. and Dimitrakopoulos, R. 2009. Block simulation of multiple correlated variables. Mathematical Geosciences. vol. 41, no. 2. pp. 215-237. http://dx.doi.org/10.1007/s11004-008-9178-0

Dimitrakopoulos, R. (ed.). 2018. Advances in Applied Strategic Mine Planning. Springer Nature, Heidelberg. doi: 10.1007/978-3-319-69320-0

De Neufville, R. and Scholtes, S. 2011. Flexibility in Engineering Design. MIT Press, Cambridge, MA. 293 pp.

Del Castillo, F. 2018. Dynamic simultaneous optimization of mineral value chains under resource uncertainty. $\mathrm{PhD}$ thesis, McGill University, Montreal.

Del Castillo, F. and Dimitrakopoulos, R. 2014. Joint effect of commodity price and geological uncertainty over the life of mine and ultimate pit limit. Mining Technology, vol. 123, no. 4. pp. 207-219. https://doi.org/10.1179/1743286314Y.0000000069

Del Castillo, F. and Dimitrakopoulos, R. 2019. Dynamically optimizing the strategic plan of mining complexes under supply uncertainty. Resources Policy, vol. 60(C). pp. 83-93. https://doi.org/10.1016/j.resourpol.2018.11.019

Dixir, A. and PINDYcK, R. 1994. Investment Under Uncertainty. Princeton University Press.

Dowd, P. 1994. Risk assessment in reserve estimation and open-pit planning. International Journal of Rock Mechanics and Mining Sciences \& Geomechanics Abstracts, vol. 32, no. 4. pp. 148-154. https://doi.org/10.1016/0148-9062(95)97056-0

EichHorn, M., Krumins, T., ZunTI, L., and RufF, F.C. 2014. Capacity enhancement at Newmont Mining Corporation's Twin Creek's whole ore pressure oxidation facility. Canadian Instutute of Mining, Metallurgy \& Petroleum: Hydrometallurgy, vol. 1, no. 735-749. pp. 80-90.

FARMER, I. 2016. Stochastic mining supply chain optimization: A study of integrated capacity decisions and pushback design under uncertainty. MEng thesis, McGill University, Montreal. https://pdfs.semanticscholar. org/755d/38a5804034d03d393e93043aa90743a60f62.pdf

GERSHON, M.E. 1983. Optimal mine production scheduling: evaluation of large scale mathematical programming approaches. International Journal of Mining Engineering, vol. 1, no. 4. pp. 315-329. https://doi.org/10.1007/BF00881548

GithiRiA, J. and Musingwini, C. 2019. A stochastic cut-off grade optimization model to incorporate uncertainty for improved project value. Journal of the Southern African Institute of Mining and Metallurgy, vol. 119. pp. 217-228. doi: 10.17159/2411-9717/2019/v119n3a1

Godoy, M. and Dimitrakopoulos, R. 2004. Managing risk and waste mining in longterm production scheduling of open-pit mines. SME Transactions, vol. 316, no. 3. pp. $43-50$

GoodfeLLow, R. 2014. Unified modelling and simultaneous optimization of open pit mining complexes with supply uncertainty. PhD thesis, McGill University, Montreal. http://digitool.library.mcgill.ca/webclient/StreamGate?folder $\mathrm{id}=0 \&$ dvs $=1575644597071 \sim 332$

Goodfellow, R. and Dimitrakopoulos, R. 2016. Global optimization of open pit mining complexes with uncertainty. Applied Soft Computing, vol. 40. pp. 292-304. https://doi.org/10.1016/j.asoc.2015.11.038

Goodfellow, R. and Dimitrakopoulos, R. 2017. Simultaneous stochastic optimization of mining complexes and mineral value chains. Mathematical Geosciences, vol.49, no. 3. pp. 341-360. https://doi.org/10.1007/s11004-017-9680-3

GoovAERTS, P. 1997. Geostatistics for Natural Resources Evaluation. Oxford University Press, New York

Groeneveld, B. and Topal, E. 2011. Flexible open-pit mine design under uncertainty. Journal of Mining Science, vol. 47, no. 2. pp. 212-226. https://doi.org/10.1134/S1062739147020080

Groeneveld, B., Topal, E., and Leenders, B. 2012. Robust, flexible and operational mine design strategies. Mining Technology, vol. 121, no. 1. pp. 20-28. https:// doi.org/10.1179/1743286311Y.0000000018 


\section{Adaptive simultaneous stochastic optimization of a gold mining complex: A case study}

GuPTA, V. and Grossmann, I.E. 2017. Offshore oilfield development planning under uncertainty and fiscal considerations. Optimization and Engineering, vol. 18 no. 1. pp. 3-33. https://doi.org/10.1007/s11081-016-9331-4

Hustrulid, W. and Kutcha, M. 2006. Open Pit Mine Planning and Design. 2nd edn. Taylor \& Francis, London.

KHAN, A.,and AsAD, M.W.A. 2019. A method for optimal cut-off grade policy in open pit mining operations under uncertain supply. Resources Policy, vol. 60. pp. 178-184. doi: 10.1016/j.resourpol.2018.12.003

Kirkpatrick, S., Gelatt, C., and Vecchi, M. 1983. Optimization by simulated annealing. Science, vol. 220, no. 4598. pp. 671-680. https://doi.org/10.1126/ science.220.4598.671

Levinson, Z. and Dimitrakopoulos, R. 2019. Simultaneous optimization of an open-pit gold mining complex with waste management and cut-off grade optimization. International Journal of Mining, Reclamation and Environment. https://doi.org/10.1080/17480930.2019.1621441

Li, Y., HuANG, G., NiE, S., and Liv, L. 2008. Inexact multistage stochastic integer programming for water resources management under uncertainty. Journal of Environmental Management, vol. 88. pp. 93-107. https://doi.org/10.1016/j.jenvman.2007.01.056

Mai, N. L., Topal, E., Erten, O., and Sommerville, B. 2018. A new risk-based optimisation method for the iron ore production scheduling using stochastic integer programming. Resources Policy. doi: 10.1016/j.resourpol. 2018.11.004

Menabde, M., Froyland, G., Stone, P., and Yeates, G. 2007. Mining schedule optimisation for conditionally simulated orebodies. Orebody Modelling and Strategic Mine planning: Uncertainty and Risk Management Models. Spectrum Series vol. 14. Australasian Institute of Mining and Metallurgy, Melbourne. pp. 379-384. https://doi.org/10.1007/978-3-319-69320-0_8

Montiel, L. and Dimitrakopoulos, R. 2018. Simultaneous stochastic optimization of production scheduling at Twin Creeks Mining Complex, Nevada. Mining Engineering, vol. 70, no. 12. pp. 12-20.

Montiel, L. and Dimitrakopoulos, R. 2015. Optimizing mining complexes with multiple processing and transportation alternatives: An uncertainty-based approach. European Journal of Operational Research, vol. 247, no. 1. pp. 166-178. https://doi.org/10.1016/j.ejor.2015.05.002

Montiel, L., and Dimitrakopoulos, R. 2017. A heuristic approach for the stochastic optimization of mine production schedules. Journal of Heuristics, vol. 23, no. 5 pp. 397-415. https://doi.org/10.1007/s10732-017-9349-6

Pimentel, B., Mateus, G., and Almeida, F. 2010. Mathematical models for optimizing the global mining supply chain. Intelligent Systems in Operations: Methods, Models, and Applications in the Supply Chain. Business Science Reference, Hershey, PA. pp. 133-163. https://doi.org/10.4018/978-1-61520-605-6.ch008

RAvENSCRoFT, P. (1992. Risk analysis for mine scheduling by conditional simulation. Transactions of the Institution of Mining and Metallurgy Section A: Mining Industry, vol. 101. pp. 104-108. https://doi.org/10.1016/0148-9062(93)90969-K

Rossi, M. and Deutsch, C. 2014. Mineral Resource Estimation. Springer, Dordrecht, The Netherlands. https://doi.org/10.1007/978-1-4020-5717-5

SaliBA, Z. and Dimitrakopoulos, R. 2018. Simultaneous stochastic optimization of an open pit gold mining complex with tailings management. Mining Technology, vol. 128 , no. 4 . doi: $10.1080 / 25726668.2019 .1626169$

Singh, K.J., PhilpotT, A.B., and Wood, R.K. 2009. Dantzig-Wolfe decomposition for solving multistage stochastic capacity-planning problems. Operations Research, vol. 57, no. 5. pp. 1271-1286. https://doi.org/10.1287/opre.1080.0678

Thomas, K. and Pearson, M. 2016. Pressure oxidation overview. Gold Ore Processing. Thomas, K. and Pearson, M.(eds). Elsevier. Chapter 21, pp. 341-358. https://doi.org/10.1016/B978-0-444-63658-4.00021-9

WhitTLE, J. 1999. A decade of open pit mine planning and optimization The craft of turning algorithms into packages. APCOM'99: Proceedings of the 28th International Symposium on Computer Applications in the Minerals Industries Golden, CO, 20-22 October 1999. Dagdelen, K. (ed.). Colorado School of Mines. pp. $15-23$.

\section{Appendix A}

Adaptive simultaneous stochastic optimization sets, parameters, and decision variables

\section{Sets and Parameters}

$M \quad$ Set of open-pit and underground mines

$P \quad$ Set of processors

$W \quad$ Set of waste facilities

$S \quad$ Set of stockpiles

$G \quad$ Set of groups or bins for different cut-off

grades $g \in G$

$\mathrm{T} \quad$ Set of scheduled time periods $t \in \mathrm{T}$
S Set of simulated orebody scenarios $S \in \mathrm{S}$ where there are $\mathrm{S}_{n} \subseteq \mathrm{S}$ scenarios that belong to the root, these scenarios are partitioned into $\mathrm{S}_{n 1}$ and $\mathrm{S}_{n 2}$ when branching occurs therefore $\mathrm{S}_{n 1} \cup \mathrm{S}_{n 2}=\mathrm{S}_{n}$ and $\mathrm{S}_{n 1} \cap \mathrm{S}_{n 2}=\varnothing$

$\mathrm{P} \quad$ Set of primary attributes $p \in \mathrm{P}$

$\mathrm{H} \quad$ Set of hereditary attributes $h \in \mathrm{H}$

$\mathrm{K} \quad$ Set of available capital investments $k \in \mathrm{K}$. There are two different subsets used to describe the different types of investments branching $\left(K^{*}\right)$ and nonbranching $\left(K^{=}\right)$, where $K^{*} \cup K^{=}=K$

$O(g) \quad$ Set of locations where the groups of materials $g$ can be delivered

$B_{\mathrm{m}} \quad$ Set of mining blocks $b \in B_{m}$ from mine $m \in \mathrm{M}$

$\beta_{p, b, s} \quad$ Parameter that defines the set of simulated primary attribute $p$ for block $b$ in scenario $s$

$r_{p, i, t, s} \quad$ Parameter that describes the recovery of each attribute $p$ at location $i \in P$ in each scenario $s$

$R \quad$ Representativity measure that describes the confidence interval for branching $R \in(0,0.5)$

$t \quad$ Time window used to stabilize solutions where $\omega$ represents the number of periods to search

$N \quad$ Defines the minimum number of scenarios in a branch required for further branching periods $(t+1) \in \mathrm{T}$

$\tau_{k} \quad$ Lead time to assemble or construct a capital investment $k \in K$

$\lambda_{k} \quad$ Life expectancy of each capital investment $k \in K$

$\kappa_{k, h} \quad$ Unitary increase in capacity that each investment $k \in$ $K$ leads to for each attribute $h \in \mathrm{H}$

$p_{k, t}^{K} \quad$ Discounted purchase cost for each investment $k \in K$ for each period $t \in \mathrm{T}$

$\psi_{k} \quad$ The periodicity of the investment $k \in K$

$L_{h, i, t} U_{h, i, t}$ The static upper and lower bounds for each hereditary attribute $h \in \mathrm{H}$, location $i \in M \cup S \cup P \cup W$, and period $t \in \mathrm{T}$

Decision Variables

$v_{p, i, t, s}, v_{h, i t, s}$ Quantify the value of primary $(p)$ and hereditary $(h)$ attributes at each location $i \in M \cup S \cup P \cup W$ in period $t$ under scenario $S$, respectively

$x_{b, t, s} \quad$ A set of binary extraction sequence decision variables that denotes if a block $b$ is extracted in period $t$ in scenario $s$ as 1 , otherwise 0

$z_{g, j, t, s} \quad$ A destination policy decision variable that takes a value of 1 if blocks in group $g$ are sent to destination $j$ $\in O(g)$, in period $t \in \mathrm{T}$

$y_{i, j, t s} \quad$ A continuous processing stream decision variable that defines the portion of product that is sent from one destination $i \in S \cup P$ to destination $j \in \mathrm{O}(i) \subseteq S \cup \mathrm{P}$ in period $t \in \mathrm{T}$ and scenario $S \in \mathrm{S}, y_{i, j, t, s} \in[0,1]$

$\omega_{k, s, t} \quad$ A capital investment decision variable that defines if a capital investment $k \in K$ is executed in period $t \in \mathrm{T}$ and scenario $s \in \mathrm{S}$

$\sigma_{k, t, s} \quad$ The number of investments undertaken for each investment $k \in \mathrm{K}$ in period $t \in \mathrm{T}$ and scenario $s \in \mathrm{S}$

$\mathrm{u}_{k^{*}, t} \quad$ A binary variable equals unity when the design branches over option $k^{*} \in K^{*}$ in node $n$ in period $t \in \mathrm{T}$, otherwise 0

A A binary variable that activates the non-anticaptivity constraints taking on the value 0,1 . 